\title{
APÊNDICE A QUESTIONÁRIO ROMA III DE ALERTA PSICOSSOCIAL PARA DISTÚRBIOS FUNCIONAIS GI
}

Am J Gastroenterol. 2012;105:795; doi 19.1038/ajg.2012.71

\section{INSTRUÇÕES}

As seguintes perguntas são para fins de triagem e estão unidas a um contexto clínico e não foram feitas para propósitos de pesquisa. Elas ajudam a identificar problemas psicossociais que pacientes com DFGIs enfrentam frequentemente. Para cada questão, há duas recomendações possíveis:

a. Há um problema (itens em negrito) que o médico deve reconhecer, discutir com o paciente, e optar por uma ação apropriada, que pode incluir a indicação de um especialista em saúde mental e/ou tratamento com farmacoterapia.

b. Uma "situação mais séria" (marcada com com que o médico é aconselhado a lidar pessoalmente, ou considerar a indicação de um profissional em saúde mental (psiquiatra, psicólogo ou outro) simultaneamente ou antes do tratamento para DFGI. Estas são referidas como situações "bandeira vermelha" para salientar sua importância.

Observação: É necessário investigar mais para decidir corretamente a ação mais apropriada de acordo com a natureza e a gravidade dos problemas psicossociais.

Este questionário foi produzido pela Subcomissão de Aspectos Psicossociais dos Distúrbios Funcionais GI para Rome III: Francis Creed, MD (Presidente), Rona Levy, PhD (Co-Presidente), Lawrence Bradley, PhD, Douglas A. Drossman, MD, Carlos Francisconi MD, Bruce D. Naliboff, PhD, e Kevin W. Olden, MD.

\section{QUESTIONÁRIO ROMA III DE ALERTA PSICOSSOCIAL}

\section{Pergunta \\ 1. Pergunta sobre ansiedade}

Na semana passada, você se sentiu tenso ou "nervoso"?

\section{Resposta}

Na maior parte do tempo

$\checkmark$ Por muito tempo

De vez em quando

$\checkmark$ De maneira nenhuma

\section{Pontuação}

“Na maior parte do tempo" ou "Por muito tempo" indicam um problema (provável distúrbio de ansiedade).

\section{Lógica para pontuação}

Esta pergunta foi trazida da Escala Clínica de Ansiedade e Depressão (HADS). As respostas "Na maior parte do tempo" ou "Por muito tempo" identificam a maioria dos distúrbios de depressão ou de ansiedade nesta população.

Estes pacientes tem uma pontuação HADS de ansiedade ruim $13,3(\mathrm{dp}=3,6)$ comparada a $6,0(\mathrm{dp}=2,5)$ para aqueles que responderam "De vez em quando" ou "De maneira nenhuma" $(1,2)$.

\section{Bandeira Vermelha}

Pacientes que respondem "Na maior parte do tempo" representam $24 \%$ de pacientes com distúrbios gastrointestinais funcionais. A pontuação HADS de ansiedade deles foi 15,7 $(\mathrm{dp}=3,2)$ (intervalo: $10-21)^{(1,2)}$.

(Observação: a pontuação HADS de ansiedade 10 ou mais, indica um caso provável de ansiedade Consequentemente este nível de ansiedade merece um encaminhamento especial para manejo comportamental destes pacientes antes do tratamento dos DFGI.) 
Pergunta Resposta Pontuação

\section{Pergunta sobre depressão}

Na semana passada, você se sentiu desanimado ou deprimido?

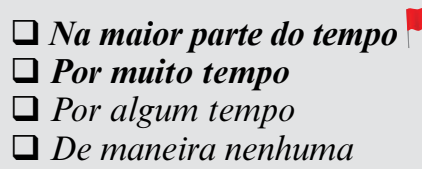

“Na maior parte do tempo" $e$ "Por muito tempo" indicam um problema (provável distúrbio de depressão).

\section{Lógica para Pontuação}

Esta questão foi trazida do Formulário-36 (SF-36, pergunta 9f). As respostas "Na maior parte do tempo" e "Boa parte do tempo" identificam pacientes DFGI, cujas médias de escores HADS de depressão foram $9,0(\mathrm{dp}=3,0)$ comparadas a 5,0 $(\mathrm{dp}=3,6)$ para o restante ${ }^{(1,2)}$.

\section{Bandeira Vermelha.}

Pacientes que respondem "Na maior parte do tempo" a esta pergunta: representam $12,8 \%$ de pacientes com DFGI. Sua média de escore HADS de depressão foi $9,4(\mathrm{dp}=2,6)^{(1,2)}$. Somado a isso, quase todos os pacientes que responderam " $\mathrm{Na}$ maior parte do tempo" para esta pergunta, também responderam “Na maior parte do tempo" para a pergunta de ansiedade. Consequentemente, usando ambas as perguntas de ansiedade e depressão, nosso critério de bandeira vermelha inclui os $15 \%$ que estão no topo entre os pacientes mais ansiosos/deprimidos com DFGI.

\section{Pergunta sobre ideias suicidas}

Recentemente você se sentiu deprimido a ponto de querer se machucar ou se matar?

\section{$\square$ Frequentemente \\ De vez em quando \\ $\square$ De maneira nenhuma}

\section{Pergunta sobre severidade da dor}

Durantes as últimas 4 semanas, qual a intensidade de dor corporal você sentiu?

$\square$ Muito forte
$\square$ Forte
$\square$ Moderada
$\square$ Leve
$\square$ Nenhuma

"Frequentemente" ou "De vez em quando" indicam um problema. O médico deve pedir ao paciente para descrever melhor seus sentimentos atuais e qualquer plano específico.

\section{Lógica para pontuação}

Esta pergunta não foi testada empiricamente, mas tem validade de rosto (ou de face, que significa aquele tipo de validade que verifica basicamente se um determinado instrumento parece medir aquele conceito clínico em pauta). O médico não deve se retrair em fazer mais perguntas para quem responde "Frequentemente" ou "De vez em quando" Todas as evidências sugerem que uma melhor maneira de prevenir suicídio começa com a preparação do médico para fazer tais perguntas.

\section{“Muito forte" ou "Forte" indicam um problema.}

\section{Lógica para pontuação}

Pacientes que respondem "Forte" ou "Muito Forte" a esta pergunta ( 7 do SF-36) representam $24 \%$ daqueles com distúrbios gastrointestinais funcionais. A média de pontuação no sumário do componente físico do SF foi 30,1 $(\mathrm{dp}=8,5)^{(1,2)}$, que são dois desvios padrões abaixo do padrão da população. 


\section{Pergunta \\ Resposta \\ Pontuação}

\section{Pergunta sobre limitação}

Durante as últimas 4 semanas, como a dor (ou outros sintomas) interferiram nas suas atividades normais (incluindo trabalhar tanto fora quanto em casa)? $\square$ Extremamente

Muito

Moderadamente

Um роисо

De maneira nenhuma
"Extremamente" ou "Muito" indicam um problema.

\section{Lógica para pontuação}

Pacientes que respondem "Muito" ou "Extremamente" a esta pergunta ( 8 do SF-36) representam

$26 \%$ daqueles com distúrbios gastrointestinais funcionais. A má pontuação no sumário do componente físico SF foi $28,9(\mathrm{dp}=8,2)^{(1,2)}$, que são dois desvios padrões abaixo do padrão da população.

\section{Pergunta sobre a capacidade de lidar com as dificuldades ('coping')}

Quando eu sinto dor (ou outros sintomas) digo para mim mesmo "isto é terrível e acho que nunca vai melhorar"

\section{$\square$ Sempre \\ Algumas vezes D Nunca}

"Sempre” ou "Algumas vezes" indicam um problema.

\section{Lógica para Pontuação}

Esta pergunta é do formulário de um item do "Questionário de Estratégias para Lidar com Dificuldades" (Coping Strategies Questionnaire). Ele foi usado em um estudo sobre dor crônica ${ }^{(3)}$, mas ainda tem que ser validado em pacientes com DFGI.

\section{Pergunta sobre abuso}

É muito comum as
pessoas terem sofrido
abuso emocional,
físico ou sexual em
algum momento de
suas vidas, e isto
pode afetar a maneira
como lidam com as
condições médicas.
Isto já aconteceu com
você?

Se a resposta é "Sim", o médico deve perguntar:

"Isto está causando a você sofrimento na sua vida", e "Você gostaria de ver alguém e discutir isso com mais detalhes?"

Se o paciente concorda que ele/ela está muito aflito e gostaria de ver alguém, então isto deve ser uma situação "bandeira vermelha" (i.e., o médico deve considerar um encaminhamento precoce para um profissional em saúde mental, contanto que o paciente concorde). Esta orientação vem de revisões e recomendações publicadas na literatura ${ }^{(4)}$.

\section{REFERÊNCIAS}

1. Biggs AM, Aziz Q, Tomenson B, Creed F. Effect of childhood adversity on health related quality of life in patients with upper abdominal or chest pain. Gut. 2004;53:180-6.

2. Fiddler M, Jackson J, Kapur N, Wells A, Creed F. Childhood adversity and frequent medical consultations. General Hospital Psychiatry. 2004;26:367-77.
3. Jensen MP, Keefe FJ, Lefebvre JC, Romano JM, Turner JA. One- and two-item mea- sures of pain beliefs and coping strategies. Pain. 2003;104:453-69.

4. Drossman DA, Talley NJ, Olden KW, Leserman J, Barreiro MA. Sexual and physical abuse and gastrointestinal illness: review and recommendations. Ann Intern Med. 1995; 123:782-94. 